\title{
Maria Gabriella Micale. "A Stamp Seal from the Acropolis of Tell Mardikh: A Syrian Style within the Persian Empire?"
}

\section{Astrid Nunn}

\author{
(2) OpenEdition \\ Journals \\ Édition électronique \\ URL : http://journals.openedition.org/abstractairanica/49446 \\ DOI : 10.4000/abstractairanica.49446 \\ ISBN : 1961-960X \\ ISSN : 1961-960X \\ Éditeur : \\ CNRS (UMR 7528 Mondes iraniens et indiens), Éditions de l'IFRI
}

\section{Référence électronique}

Astrid Nunn, « Maria Gabriella Micale. "A Stamp Seal from the Acropolis of Tell Mardikh: A Syrian Style within the Persian Empire?" », Abstracta Iranica [En ligne], Volume 40-41 | 2019, document 59, mis en ligne le 30 octobre 2019, consulté le 17 avril 2021. URL : http://journals.openedition.org/ abstractairanica/49446 ; DOI : https://doi.org/10.4000/abstractairanica.49446

Ce document a été généré automatiquement le 17 avril 2021

Tous droits réservés 


\title{
Maria Gabriella Micale. "A Stamp Seal from the Acropolis of Tell Mardikh: A Syrian Style within the Persian Empire?"
}

\author{
Astrid Nunn
}

\section{RÉFÉRENCE}

Maria Gabriella Micale. "A Stamp Seal from the Acropolis of Tell Mardikh: A Syrian Style within the Persian Empire?" in Agnese Vacca, Sara Pizzimenti, Maria Gabriella Micale (eds.). A Oriente del Delta. Scritti sull'Egitto ed il Vicino Oriente antico in onore di Gabriella Scandone Matthiae. (Contributi e Materiali di Archeologia Orientale (CMAO) XVIII). 2018, p. 389-422

L'A. profite des Mélanges pour une égyptologue - Gabriella Scandone Matthiae - qui travailla toute sa vie sur les rapports entre l'Egypte et le Levant pour présenter un scaraboïde trouvé lors des fouilles de 2010 à Ebla. Il a été découvert dans un puits dans un contexte d'époque achéménide. La surface est divisée en deux registres par un disque ailé (le hiéroglyphe $\mathrm{nb}$ ), au-dessus duquel se trouvent un griffon couchant, un signe ankh, une étoile et un signe non identifié. Sous le nb sont représentés un animal couchant à corne avec une étoile et un croissant de lune. Tous ces éléments sont bien connus depuis de Fer II, et pourtant, l'A. n'a pas trouvé d'image similaire. Une analyse stylistique la fait cependant pencher pour l'époque achéménide, auquel cas se pose la question de l'origine et de l'apport spécifiquement syrien. 


\section{AUTEURS}

\section{ASTRID NUNN}

Université de Munich 